\title{
El empaste y el grumo. Narración y pintura en Juan José Saer
}

\author{
Miguel Dalmaroni*
}

\section{Resumen}

Los modos de la escritura de Saer persiguen efectos como los que el escritor identifica en la pintura que prefirió, entre Van Gogh y Pollock, entre Estrada y Espino. Conceptualizamos esos modos mediante la figura de un trabajo que busca pasar del plano al "empaste", al "grumo", a la pictorización en relieve; y analizamos sus relaciones con el método narrativo de Saer.

\section{Palabras clave}

Saer. Glosa. Literatura y pintura. Forma espacial. Narrativa argentina.

No pinto. Trabajo en arcilla y a veces en cobre y una vez en un pedazo de piedra con cincel y maza. Sienta. [...] Esto es lo que hago: algo que se puede tocar, levantar, algo que pese en la mano, que se pueda mirar de atrás, que desplace aire y desplace agua.

Faulkner, Las palmeras salvajes (en traducción de Borges, 2006, p. 39)

[...] consiste en revivir lo vivido con la fuerza de una visión, en un proceso instantáneo [...] Más que con el realismo de la fotografía, creo que el procedimiento se emparienta con el de ciertos pintores que emplean capas sucesivas de pintura de diferente densidad para obtener una superficie rugosa, como si le tuviesen miedo a la extrema delgadez de la superficie plana.

Saer, "Razones" (1986, p. 18).

1. En su deconstrucción de "la tercera Crítica" kantiana, Derrida sostiene la artisticidad y, más aún, la corporeidad de ciertas escrituras. El texto de Kant se puede leer como "una obra de arte, un cuadro", "una especie de arquitectura", anota Derrida, que nos libra de empezar por los cimientos hasta llegar al techo: "Se debería poder comenzar por todas partes y seguir cualquier orden". La proposición tiene su ejemplar de procedencia en lo que Derrida denomina "el objeto de arte espacial, comúnmente llamado plástico", que "no prescribe necesariamente un orden de lectura. Puedo desplazarme delante de él, comenzar por lo alto o por lo bajo, a veces dar vueltas en

\footnotetext{
${ }^{*}$ UNLP - CONICET, Argentina.
} 
torno de él". Un objeto que, como le dice Carlota a Wilbourne en Las palmeras salvajes, "se puede tocar, levantar, algo que pese en la mano, que se pueda mirar de atrás, que desplace aire". Ahora bien ¿cuál es la articulación que permite a Derrida pasar de la plástica a la escritura y al libro? También los "objetos de arte temporales (discursivos o no)" son arte espacial, cuando "cierta fragmentación, una puesta en escena espacial precisamente (una partición efectiva o virtual), permite comenzar en varios lugares, hacer variar el sentido o la velocidad" (Derrida, 2001, pp. 61-63).

El argumento de Derrida remite a las varias poéticas y tradiciones críticas que han explorado caracterizaciones plásticas de la literatura. "Spatial Form in Modern Literature" de Joseph Frank abrió, como se sabe, una discusión en torno de la tesis según la cual novelistas alejados de la narración tradicional, aspiraban a producir un efecto de espacialidad semejante al de las artes visuales. Al retomar más tarde el problema, W.J.T. Mitchell desestimó la oposición espacial/temporal, hizo notar que las formas literarias siempre son espaciales, y propuso en cambio la distinción entre forma "lineal" y forma "tectónica" (Frank, 1945; Mitchell, 1980). ${ }^{1}$ Sugerir que "literatura espacial" es una tautología, mientras se reserva para un tipo de narrativa la calificación de "lineal" permitiría, a su vez, retomar ese texto de Benjamin donde figura su célebre apotegma acerca de lo que el arte hace: "Cepillar la realidad a contrapelo". El tema de ese ensayo es el arte novelístico de Julian Green, quien recuerda Benjamin- ha sido pintor y escribe como tal. Lo que, a propósito de Green, Benjamin quiere destacar es, sobre todo, el espesor antidiscursivo de lo que merece, en literatura, el nombre de arte. En la noción de antidiscurso, que tiene su explícita versión saeriana en el ensayo "La narración-objeto", ${ }^{2}$ la literatura es una energía o una fuerza que interviene la materia ajena de los discursos: corta el curso, suspende esa especialidad lineal de la narratividad y de la lengua misma que damos por natural, y manifiesta a la vez algo que no tenía lugar en los regímenes disponibles de sensorialidad ni de decibilidad. "Nunca ha estado la novela tan lejos del naturalismo como en esta obra [...]. El arte es duro. No quiere desarrollar 'una cosa de otra'", anota Benjamin. Por eso, la noción clave de la lectura benjaminiana de Green, lo mismo que en sus ensayos sobre Proust, es la de "presentización". La novelística de Green de ningún modo "describe", ni en ella nada "vive"; por el contrario, allí un "ojo" mira y presentiza "apariciones" que no han surgido de "vivencia" alguna sino de "una visión". Lo presentizado, obviamente, resulta antidiscursivo porque es, en extremo, ajeno al discurrir. Está eso y sólo eso que, en una mera compostura de presente, se da en "visión". Se diría un sensorial neto, que resulta no de una visualidad planística sino de "penetrar -anota Benjamin- hasta el fondo de las cosas" (Benjamin, 1990, pp. 112-114). El arte de la novela tectónica se aleja de la rutina maquinal del "tapicero" que transcurre en la superficie del lenguaje, contradice el curso y propicia los recorridos multidireccionales de lo espeso; lo espeso -conviene advertirlo- como una imposibilidad, es decir como un visible, un audible, un tangible del que no disponíamos

1 Sobre el tema de la "forma espacial" véase Gabrieloni (2008); también "Spatial form" en Makaryk (1993).

2 Hemos tenido en cuenta además la teoría de la lírica como "antidiscurso" propuesta por Stierle (1977). 
en los posibles de sensorialidad. Para decirlo con ese Sartre que, fascinado por Van Gogh, suena tan saeriano: se trata de la "figuración engañosa" capaz de "encarnar" un "mundo inmenso" en "el empaste", en la "pasta espesa" del Campo de trigo con cuervos (Sartre, 1977, pp. 288-289). Sartre, creo, quiere hacer explícito que la tela de Van Gogh es "engañosa" respecto de la ilusión figurativa, en un sentido próximo al Magritte que anota bajo el dibujo que "Esto no es una pipa" o, más directamente, igual que Saer cuando insiste en que, debido al modo en que Van Gogh abre lo que creíamos haber visto o poder ver, allí ya no hay ni campo, ni trigo, ni cuervos.

2. En "Transgresión" (En la zona, 1960) Saer colgó una reproducción de Campo de trigo de los cuervos en el cuarto de Tomatis. A partir de ese comienzo, las "formaciones" en que su literatura quiere tentar una experiencia se traman con la pintura: tomas de posición, preferencias de gusto o proposiciones teóricas; invención ficcional de pinturas y pintores; símiles descriptivos explícitamente pictóricos. Recordemos algunos momentos de esa conjunción: el epígrafe de Muir en Cicatrices, donde se avisa que la novela es "Imaginary picture" y se anticipa, entonces, la importancia que tendrá The Picture of Dorian Gray en el relato; el negro pleno de esa especie de mancha suprematista que ocupa el sueño de Layo en El limonero real; la preferencia por el marco y por la pared entre cuadro y cuadro en "Pensamientos de un profano en pintura", que es una variante -a su vez- de la tela enteramente blanca que pinta Héctor en "A medio borrar"; Malevich en La mayor, el expresionismo abstracto en Glosa; la mordaz benevolencia de Tomatis hacia el realismo candoroso de un pintor de academia en Lo imborrable; la analogía entre las maneras pictórica y literaria de componer en "Línea contra color"; Jackson Pollock en El río sin orillas para ilustrar ese efecto visual singularísimo, previo incluso a la primera lectura, que permite reconocer como suyo y sólo suyo un poema de Juan L. Ortiz y otorgarle, así, "ese estatuto envidiable de objeto único que es la finalidad principal del arte" (Saer, 1991, p. 228, 236).

Entre las preferencias de Saer se contó siempre el arte abstracto, tanto en su variante geométrica -Rothko, Kandinsky, Malevich, Mondrian- como en la afiebrada de los regueros aleatorios de Pollock, las tintas de Henri Michaux, las témperas y gouaches de Mark Tobey. Al mismo tiempo, se interesó por Giorgio Morandi, y en Francia frecuentó al español neofigurativo Eduardo Arroyo. Esa perspectiva ecléctica o, mejor profana, nos devuelve a los pintores argentinos con quienes Saer se vinculó desde su primera juventud. Fernando Espino (Santa Fe, 1931-1991), autor de la geometría que ilustra la portada de Palo y hueso (1965), fue para Saer, desde que lo conoció hacia 1957, un artista ejemplar. Si es cierto que la abstracción concretista predomina en la obra de Espino, aún en sus etapas más abstractas, geometrizadas y monocromáticas, se destacan momentos y series enteras de intensa expansión de los colores y de emergencia reiterada de una figuratividad tenue e indecidible pero, a la vez, marcada. Por otra parte, la de Espino es una obra que superpone materiales y texturas diferentes, que dibuja y pinta pero también estampa, ahúma, corta, cala, hiende, raya, troquela, perfora, ensambla, rasga. Entre fines de los 50 y su partida a Francia en 1968, Saer parece haber frecuentado también a los jóvenes plásticos antiacademicistas de Rosario y de Santa Fe: los modernistas de su ciudad que se reunían en "El Galpón", el informalismo y los derrames tempestuosos de Celia 
Schneider (Paraná, 1934), entre otros. Más tarde se interesaría en los relieves constructivistas de su amigo Adolfo Estrada, argentino residente en España (el símil saeriano entre la escritura y la pintura rugosa lograda tras sucesivas capas de pintura parece referido casi literalmente a la técnica de Estrada). Pero a la vez, Saer nunca desdeñó las experiencias de pintores argentinos de generaciones anteriores, como Leónidas Gambartes y Juan Grela, y es muy improbable que no se haya interesado en la figuración formalizada y puesta en fuga de artistas de "la zona" como Ricardo Supisiche. Es posible que una clave para entender esa galería esté en la estrecha amistad que desde mediados de los 60 mantuvo Saer con Juan Pablo Renzi (19401992), el conceptualista de Rosario que protagonizó algunos de los momentos más combativos durante la emergencia de las neovanguardias argentinas, algunas de cuyas obras ilustran varias portadas de libros de Saer.

Lo que el autor de La grande no podía sino ver en las obstinaciones y búsquedas de Espino, de Renzi, de Estrada, era una adiestrada intimidad con el espesor de lo real, que comenzaba en la consideración sin complacencias de la materia y de las posibilidades de apropiación artística que ofrecían no sus atributos sino sus texturas, sus contornos, sus densidades, su lugar en el espacio, la resistencia muda de una sensorialidad no hablada ni vista por la civilización en todo aquello que la civilización, para sustraérnoslo, nos entrega hablado y mostrado hasta el hartazgo. "Trato de penetrar en todo lo que se me presenta. [...] En Rosario, me acuerdo, una vez fui a dar una vuelta con otros pintores [...]. Pasamos por un basural y yo me quedé ahí mirando. Los otros se aburrían. [...] Después, poco a poco, se fueron entusiasmando, y al final se llevaron un montón de cosas" (Espino, 2000, p. 77). La frase, que es de Espino, recuerda la mirada del Saer que en Nadie nada nunca y en El río sin orillas convierte en esculturas desechos automotrices abandonados, sofocados a medias por la maleza -un camión ya en desuso ganado por la herrumbre, baterías, cubiertas y tambores de aceite semienterrados.

3. Saer encontraba en algunos recorridos de la pintura contemporánea los logros de una adhesión radical al materialismo filosófico menos complaciente y al negativismo estético más extremo. Así, los modos de su escritura persiguen efectos como los que Saer identifica en la obra de los pintores que mencionábamos. Es posible conceptualizar esos modos mediante la figura de un trabajo que busca pasar del plano al "empaste", al "grumo", a la pictorización en relieve. En Saer, la pintura es arteobjeto, mera corporización presente de un sensible exterior a los regímenes de sensorialidad; toca así -como la poesía- el mayor grado de cumplimiento de la finalidad del arte, lo que la convierte en el horizonte perseguido por la narración; hostiles hacia su doble condición temporal (la sucesividad del discurso y la carga de pasado de las palabras), los relatos de Saer trabajan entre la figuración descompuesta y la materiación no mimética, entre la "engañosa" referencia desfigurada y la abstracción autónoma, como en un vaivén entre el postimpresionismo y el expresionismo abstracto.

Sin pretender agotarlas aquí, es posible iniciar el recorrido que proponen estas conjeturas. 
Narrar es para Saer explorar lo real para abrirlo y suspenderlo en la incertidumbre, descomponer incesantemente lo compuesto a través de la multiplicación de miradas similares, repetidas pero nunca idénticas, que exploran el tenor material de lo sensible hasta perturbar los sentidos mediante los que la cultura impone totalidades y articula relaciones. La misma acción o el mismo objeto material (texturas, luces, colores, temperaturas, contornos) son narrados o descriptos una y otra vez, pormenorizados al extremo, en intentos sucesivos por agotarlos: trizado en recuerdos nunca fiables o en perceptos desintegrados, lo material "canta" en el relato su tenaz indeterminación (Saer, 1998, p. 173, 176). Saer conecta esa búsqueda con un llamado al ascetismo del narrador, para que "de la selva mineral de lo dado algo, imprevisible, vivo, se actualice" (Saer, 1998, p. 18; 1986a, p. 42). Esa ascesis tenaz, así, tiene una productividad nada ascética: la escritura puebla y carga una nada que, ya por completo ajena a las alucinaciones de "la realidad" que creíamos conocer, se querrá no vacía sino espesa. Es por eso que sólo parcialmente, el método narrativo saeriano impone la idea de repetición, eficaz por supuesto para describir uno de los efectos del empaste, el negativista (la historia de la poesía conoce bien lo que luego se asociaría al descubrimiento freudiano: el riesgo denegatorio de la iteración, que dramatiza el devenir y la no identidad). Pero en Saer la repetición es al mismo tiempo una de las técnicas de un proceso de aglomeración y producción de relieves. Desarticular, desfigurar todo lo visto y lo dicho, sospechar sin tregua de lo que se repite y repetirlo entonces hasta dejarlo enteramente "pulido"- es menos el propósito final del arte que la primera batalla de su búsqueda y su ascética condición sine qua non. Seguramente fue entre El limonero real (1974) y Nadie nada nunca (1980) donde el impulso negativista del método saeriano, alcanzó sus mayores expansiones. En esas dos novelas se extremaba el uso de dos procedimientos concomitantes: la descripción hiperdetallista de lo percibido en presente, como ha señalado Sarlo (1980); a la vez, la espacialización del relato por la reiteración con variaciones del mismo ciclo de sucesos, según el preciso análisis de El limonero real que propuso Gramuglio (1986). Si en esos textos el efecto semántico o filosófico es el de la corrosión de toda creencia, a la vez ponen en nuestras manos objetos escritos en que pesa la rotunda corporeidad en fondo del empaste. Imprevista, de entre el detritus pulverizado de lo posible, surge una experiencia material efímera pero indeleble, un momento irreductible -afuera del mundo- en que el desamparo se hace "evidencia cegadora": suspende todas las certidumbres, pero deja ante nosotros "un residuo de oro" (Saer, 1986, p. 18) donde se acrecientan "la rugosidad y el espesor" de un "mundo de materia pura que ha expelido de sí toda leyenda" (Saer, 2001, p. 93). No debería resultar paradójico que esa experiencia "imborrable" acapare, entonces, el único uso genuino del calificativo "dichosa".

Esta poética, además, se autofigura en un recorrido por la pintura contemporánea: su procedimiento negativo inicial está entre Van Gogh y Malevich, su consecuencia productiva entre Espino, Estrada y Pollock. Se trata siempre de "manchas" que primero testifican la "catástrofe" pero luego, cuando terminan por aglomerarse en el libro, dan no tanto mundo como, mejor, "el otro de todo mundo" (Blanchot, 2004, p. 69). 
En 1972, Saer terminó de escribir "La mayor". Allí, el método narrativo se concentraba sobre su extremo disolvente: Tomatis enfrentaba la imposibilidad de articular un mundo cuando pasaba del paródico e inútil intento de repetir la rememoración proustiana, a la desintegración de lo representado que lo amenazaba desde las manchas del cuadro de Van Gogh, donde la figuración se va reduciendo a una postulación de la cultura ahora fatalmente abierta. La pintura daba el principio constructivo de ese experimento contra lo decible, porque la pretensión de representar el puro presente como totalidad sensorial conducía, como si tradujese la discontinuidad de las pinceladas, a la agramaticalidad:

Ahora estoy estando en la punta de la escalera [...]: y ahora estoy estando en el último escalón, estoy estando en el penúltimo escalón, estoy estando en el antepenúltimo escalón ahora. En el ante antepenúltimo ahora. [...] Estuve y estoy estando. Estuve, estuve estando estando, estoy estando, estoy estando estando, y estoy ahora estuve estando, estando ahora en la terraza vacía. (Saer, 2001, p. $126,127)$

El gerundio queda abierto así, como un candoroso imposible de la lengua, y el "ahora" se sabe inenarrable. Ni siquiera es seguro que alguno de esos "ahora" pueda ser llamado "recuerdo", y en caso de que lo fuese, los recuerdos son puntos, y los puntos -olores, sabores, destellos, "manchas"- "no se pueden juntar" y terminan, luego, en la pura luminosidad enceguecida o en lo enteramente negro. En Nadie nada nunca, un episodio perceptual inexplicable divide en dos la vida de uno de los personajes, el bañero, y compone, claro, un cuadro puntillista: en medio del río, mientras se propone batir el récord de permanencia en el agua, el mundo visible se descompone de pronto ante sus ojos en una infinidad de puntos minúsculos separados por una delgada pero irreductible línea negra. Precisamente debido a esa ascesis deportiva extrema, el bañero ha sido despojado del artificio cultural de la totalización, y ya no puede darse mundo con las manchas que le entregan sus sentidos; sólo tiene ante sí fragmentos ínfimos de materia muda, negación de las relaciones que postula el imaginario: se hunde (Saer 1980, p. 114, 119).

En la acumulación repetida de perceptos fatigados por "La mayor" para sacar del "pantano" algo y no meramente puntos, el trigo y los cuervos de Van Gogh orientan un predominio cromático: entre muchos colores, destellan sobre todo el amarillo y el negro. Mientras el narrador se duerme, se le imponen dos manchas de entre sus recuerdos del día: el café negro que, sin verlo, ha imaginado que tomaban los clientes del bar, y una bufanda amarilla que sí ha visto pero que tiene ahora el mismo estatuto infundado que el café. En el final de Glosa un símil real del mismo cuadro sale al paso de Ángel Leto: a la orilla del lago sobre el que balconea la ciudad, unos pájaros negros y amarillos se lanzan una y otra vez, aterrados y enloquecidos, hacia una pelota "de plástico amarillo". Mientras la pelota, como un sol de Van Gogh, "concentra o expande radiaciones intensas", Leto "presiente cuánto les hace falta de extravío, de espanto y de confusión a las especies perdidas para erigir [...] el santuario [...] de [...] sus dioses" (Saer, 1986b, p. 282). 
4. Conviene leer el título de Glosa según esa figura del pintor que obtiene un relieve a fuerza de superponer pinceladas de igual color pero diferente densidad. Saer describió la novela, que también es una parodia de El Banquete de Platón, como despliegue del tipo poemático de la glosa, que obliga a repetir lo que se llama su "pie forzado", aquí los cinco versos que aparecen ya como epígrafe. Por supuesto, el dispositivo remite a decisiones constructivas semejantes en libros anteriores (las anáforas narrativas en El limonero real y en Nadie nada nunca). Glosa narra una conversación sobre otra conversación: mientras caminan, Leto y el Matemático glosan lo que se habría dicho en la fiesta del sexagésimo quinto cumpleaños del poeta Washington Noriega, en la que ninguno de los dos estuvo. El Matemático conoce algunos pormenores por el relato -la glosa- que le ha hecho Botón, uno de los invitados, y se dedica entonces a glosarla: la sofística conversación de la fiesta acerca de las relaciones entre error e instinto, libertad y necesidad, habría concluido con una demorada pero decisiva intervención de Washington, de cuyo contenido la glosa del Matemático -"siempre según Botón"- retiene sobre todo el ejemplo anecdótico e irónico propuesto por el venerado poeta: el comportamiento disímil de tres mosquitos que lo asediaran una noche en la soledad de su estudio. Por supuesto, el Matemático se engaña: toda su glosa se sostiene en la creencia de que la conclusión filosófica de Washington -en caso de que hubiese existido- es el pie forzado. En un alto en la caminata se han encontrado con Tomatis, quien les entrega un objeto que anticipa la escena final de los pájaros: precisamente un pie que se sabe glosa, escrito esa mañana: "En uno que se moría / mi propia muerte no vi / pero en fiebre y geometría / se me fue pasando el día / y ahora me velan a mí" (p. 11, 131, 132). Allí, en medio de la caminata y no sobre el final, comienzan a separarse los dos amigos. En la última página -ante el espectáculo de la bandada extraviada en erigir "sus dioses"- el narrador anota que Leto "está empezando a derribar los suyos" (p. 282). Sin embargo, ya sabemos que Ángel está ensordecido por fantasmas que no podrá derribar, los recuerdos del suicidio de su padre: cuando Tomatis lee el poema "Leto no lo ha escuchado" porque esos recuerdos lo distraen por completo, y pide al poeta que lea nuevamente. Tomatis repite -ya por tercera vez en la novela, que la tiene de epígrafe- la estrofa. El Matemático, en cambio, no se pierde palabra, pero además se repetirá desde ese día capas y capas del poema hasta volverlo "superficie rugosa". Le ha pedido a Tomatis la hoja con el texto, la ha guardado en su billetera, y poco después comenzará a entrever que es allí, en las "irradiaciones" de esa "materia combustible" y no en lo que escondieran "los mosquitos de Washington" donde está lo que se glosa: el reconocimiento de la nadería del yo (p. 159). Contra todas las evidencias de su racionalismo, el geómetra lo llevará para siempre consigo, en su memoria los versos y en un pliegue de su billetera la hoja de papel donde van mecanografiados: ajada y vuelta ya no "mensaje" sino "objeto" (p. 148), volverá a desplegarla, tocarla, mirarla, por el resto de su vida. Porque tras escuchar el poema por primera vez, el Matemático será asaltado por una percepción insuprimible que ya no lo abandonará: la hoja guardaba una relación secreta con fragmentos del universo, y desprenderse de ella podía "contribuir a exterminar[los]", mientras que conservarla acaso significase "preservarlos de la destrucción" (p. 150, 151). Por la repetición de la

${ }^{3}$ En el apartado 4, todos los números de páginas sin mención de autor y año remiten a Glosa (1986b). 
glosa, por la densificación "monocorde" del mismo estribillo en capas superpuestas, el arte de Saer -como las letras de Tomatis-descompone las pretensiones de la identidad y a la vez compone ese "fragmento sonoro de esencia paradójica [...] que al mismo tiempo pertenece y no pertenece al universo físico" (p. 132): el arte, presencia inesperada cuya "frecuentación nos produce" -ha escrito Saer a propósito de Espinouna cierta "reconciliación con el mundo" porque, como en la glosa, revela que la "condición mortal" nos iguala radicalmente al desatarnos de cualquier otra ilusión de identidad (Saer, 2000, p. 43). En "las últimas siete cuadras" de la caminata, la glosa se repite pero ya no en un texto que se pictoriza ni en un episodio en que lo real enloquece según la tenebrosa visión de un Van Gogh. Lo que sale al encuentro de los caminantes es ahora, desde la vidriera de una galería, una impactante tela informalista. Pertenece a Rita Fonseca -una mezcla de Pollock, Espino y Celia Schneider-, y produce el único momento extático de Leto, quien por un instante queda substraído de la leyenda familiar por esa "aglomeración sensible [...] que [...] añade, liberadora, a lo existente, delicia y radiaciones" (p. 217). Los "drippings" de Rita, que sí estuvo en la fiesta, tienen por supuesto el espesor que Saer pide para su propio arte:

\begin{abstract}
el chorreado [...] se adensa por momentos en remolinos, en manchas superpuestas varias veces, en gotas de tamaño diferente que, al estrellarse, cayendo de distinta altura, lanzadas con distinta fuerza o constituidas por distintas cantidades de pintura más o menos diluidas, se estampan por lo tanto de manera distinta cada vez [...]. Por otra parte, las manchas y los regueros tortuosos continúan hasta los bordes, los cuatro costados clavados al bastidor, de modo tal que como se comprueba que lo que ha quedado detrás del bastidor es la continuación de la superficie visible, puede deducirse con facilidad que esa parte visible no es más que un fragmento [...] No son formas sino formaciones, rastros temporariamente fijos de un fluir incesante, ¿no?, aglomeración sensible, podría decirse, en un punto preciso de la sucesión. (p. 216, 217)
\end{abstract}

Puede verse que esta extensa écfrasis subraya, como cualidad de la pintura, ese relieve donde incontables pasados se hacen presentes, empastados y corpóreos, en el ahora visionario de la tela. Inmediatamente, Leto escuchará el testimonio del Matemático sobre el método de la pintora -una sesión de action painting-. La écfrasis del cuadro y el relato de su génesis técnica iluminan qué relación específica establecen las narraciones de Saer con la pintura. Si comencé subrayando el efecto de presentización que para Saer "emparienta" su literatura con el relieve por superposición de pinceladas, es porque el escritor encuentra allí el modo de conjurar los peligros de la narratividad, cárcel acontecimentalista del pasado, que no pertenece al arte sino al ciego intercambio social -recuerdo, creencia, "leyenda", santuario de los dioses adorados por las especies extraviadas-. Con un argumento claramente benjaminiano, Saer cita la distinción de Kierkegaard entre el "acordarse", mera función pragmática, y el arte de "revivir lo vivido con la fuerza de una visión". El equivalente pictórico no planístico de ese procedimiento se repite también en una serie de objetos - plásticos, literarios o cotidianos- cuyo ápice está en los derrames de Rita Fonseca: todo el pasado está ahí en estado de puro presente matérico. En Glosa, cincuenta páginas antes de la écfrasis de la tela de Rita, una circunstancia inesperada permite al Matemático 
desplegar, o despegar más bien, porciones de su vida superpuestas entre sí y apelmazadas, igual que esos carteles que, en las paredes de las ciudades, bajo capas sucesivas de engrudo y papel impreso, forman una especie de costra de las que apenas si pueden hojearse los bordes toscos y atormentados, aunque uno sepa que en cada una de esas láminas recubiertas subsiste, invisible, una imagen. ( $p$. 165)

Pocas líneas después, es "la sucesión [...] del acaecer" la que recibe -contra la ficción cultural de su linealidad- el mismo calificativo que el procedimiento del pintor: "rugosa". Pero en la cita, el adjetivo clave es "invisible": el afiche apelmazado, el poema de Tomatis, la tela de Rita no representan, del mundo, nada. En cambio, dejan irradiando ante un nosotros suspendido de sí, el grumo ni visible ni decible de lo real. Es importante subrayar que, en el instante en que el objeto nos captura, ya no hay, en rigor, yo. Sucede con Leto, que al observar el cuadro -nunca ha visto "nada semejante"- "penetra" en la tela y se substrae por completo del mundo exterior. Sucede, en su caso muchas veces, con el Matemático, cuya fidelidad a la hoja ajada del poema de Tomatis le recuerda, en las páginas que siguen al símil del afiche, una pesadilla que glosa la glosa: el hallazgo de una cinta plana de papel, que resulta ser una larga hoja plegada en acordeón con una "mancha" que de cerca es su propio retrato. Siempre variando la expresión, la cinta interminable repite su cara en cada pliegue, y se convierte en su propia piel cuando el Matemático persiste en desplegarla, hasta advertir espantado que el juego termina en la disolución de sí. Se ha dicho que en la era de la ausencia, cuando faltan los dioses, "el arte es la intimidad de ese desamparo" porque vuelve manifiesto, "por la imagen, el error de lo imaginario, y en el límite, la verdad inasible, olvidada, que se disimula detrás de ese error" (Blanchot, 2004, p. 76). Aceptar esa intimidad, rechazar eso que las representaciones han hecho de nosotros, es el paso obligado para que, como en el arte, "algo, imprevisible, vivo, se actualice". La composición que la escritura saeriana va empastando, busca que nos ocurra lo mismo que asalta a veces a tantos personajes por "un capricho de la contingencia": en un momento de la caminata, "el hecho de estar ahí en el presente y no en la ciénaga de la memoria" produce en Leto y en el Matemático, al unísono además, "un temblor de gozo y un sobresalto de liberación", "una reconciliación salvadora", debido a "un azar convertido en don, una concatenación de los grumos dispersos de lo visible y de lo invisible, de los cuajarones inciertos de lo sólido, de lo líquido y de lo gaseoso, de lo orgánico y de lo inorgánico, de ondas y corpúsculos". En Nadie nada nunca, el Gato Garay entra en un trance similar, un "estado extraño" en que "lo que era yo [...] sabe ahora que está aquí, en el presente"; "es como si [...] razona el Gato-, una imagen fosforescente de muchos colores combinados de un modo armonioso, se hubiese reflejado [...] en mí" (Saer, 1980, p. 85, 86). Sobre el final de Lo imborrable, "una sensación inesperada de armonía" visita, azarosa, a Tomatis (Saer, 1993, p. 235). A Nula se le impone imprevisible "una presencia vívida que lo rodea, como si de pronto se acrecentara la rugosidad y el espesor de la materia", trance brevísimo que lo pone "al abrigo del tiempo, del dolor, de la muerte" (Saer, 2001, p. 93, 94). 
5. En La grande, tras el banquete final en casa de Gutiérrez, los comensales se dispersan entre la piscina y el jardín. Entonces Diana -la mujer de Nula, también pintora- dibuja en su block un esquema oval de manchas que sugieren "una vaga reminiscencia humana" (una por cada uno de los invitados) aunque son más bien abstractas. Y cuando Tomatis contempla "el cuadro vivo que parecen representar" los presentes, le pone título: "Domingo de verano en el campo. La tarde", variación evidente de Dimanche après-midi à lîle de la Grande Jatte de Georges Seurat, la declaración de principios del puntillismo (Saer, 2005, p. 409, 410, 419). Seurat aspiraba, como se sabe, a conseguir una síntesis cromática que se operaría en la retina del espectador, mientras señalaba el papel de la subjetividad como agente de articulación del mundo. En La grande, los ojos del narrador o los de Tomatis cuentan lo pintado e imaginan pintado lo que narran. Las unidades de la imaginación siguen siendo manchas, pero lo son menos de la figuración descompuesta que de la brevísima, azarosa posibilidad de esa aglomeración colorida y feliz del presente.

\section{Bibliografía}

BENJAMIN, Walter. "Tres iluminaciones sobre Julien Green". Imaginación y sociedad. Iluminaciones I. Trad. Jesús Aguirre. Madrid: Taurus, 1990, pp.105-124.

BLANCHOT, Maurice. "Kafka y la exigencia de la obra". El espacio literario. Trad. Vicky Palant y Jorge Jinkis. Barcelona: Paidós, 2004, pp. 51-76.

DERRIDA, Jacques. La verdad en pintura. Trad. María Cecilia González y Dardo Scavino. Buenos Aires: Paidós, 2001.

ESPINO, Fernando. "La trama bajo las apariencias. Entrevista con Espino". GOLA, Hugo; SAER, J. J.; PADELETTI, Hugo; ESPINO, F. La trama bajo las apariencias. La pintura de Fernando Espino. México: Artes de México, 2000, pp. 71-79.

FAULKNER, William. Las palmeras salvajes. Trad. Jorge Luis Borges. Buenos Aires: Debolsillo, 2006.

FRANK, Joseph. "Spatial Form in Modern Literature". The Sweanee Review 7/1, 1945, pp. 221-40. Part I; 7/2, 1945, pp. 433-56. Part II; 7/4, 1945, pp. 643-653. Part III.

GABRIELONI, Ana Lía. "Literatura y artes" (2008). DALMARONI, Miguel (dir.). La investigación literaria. Problemas iniciales de una práctica. Santa Fe: Ediciones Universidad Nacional del Litoral, pp. 117-139, 2009.

GRAMUGLIO, María Teresa. "El lugar de Saer". Lafforgue, Jorge (ed.). Juan José Saer por Juan José Saer. Buenos Aires: Celtia, 1986, pp. 261-299.

MAKARYK, Irena R. (ed.). "Spatial form". Encyclopedia of Contemporary Literary Theory. Toronto: University of Toronto Press, 1993, pp. 629-631.

MITCHELL, W. J. T. "Spatial Form in Literature: Toward a General Theory". Critical Inquiry, Vol. 6, No. 3, Spring, 1980, pp. 539-567. 
SAER, Juan José. En la zona. Santa Fe: Editorial Castellví, 1960.

. El limonero real. Barcelona: Editorial Planeta, 1974.

. Nadie nada nunca. México: Siglo XXI Editores, 1980.

. "Razones". Lafforgue, Jorge (ed.). Juan José Saer por Juan José Saer. Buenos

Aires: Celtia, 1986, pp. 9-24.

"Atridas y Labdacidas". Lafforgue, Jorge (ed.). Juan José Saer por Juan José

Saer. Buenos Aires: Celtia, 1986a, pp. 27-42.

Glosa. Buenos Aires: Alianza Editorial, 1986b.

. El río sin orillas. Buenos Aires: Alianza Editorial, 1991.

Lo imborrable. Buenos Aires: Alianza Editorial, 1993.

. El concepto de ficción. Buenos Aires: Ariel, 1998.

. La narración-objeto. Buenos Aires: Seix Barral, 1999.

"Una deuda en el tiempo". Gola, Hugo; Saer, J. J.; Padeletti, Hugo;

ESPINO, F. La trama bajo las apariencias. La pintura de Fernando Espino. México:

Artes de México, 2000, pp. 27-49.

. Cuentos completos. Buenos Aires: Seix Barral, 2001.

. Cicatrices. Buenos Aires: "Biblioteca Argentina La Nación", $2001 a$.

. La grande. Buenos Aires: Seix Barral, 2005.

SARLO, Beatriz. "Narrar la percepción". Punto de vista, No. 10 (noviembre), 1980, pp. 34-37.

SARTRE, Jean-Paul. "El pintor sin privilegios". Literatura y arte. Situations IV. Trad. María Scuderi. Buenos Aires: Losada, 1977, pp. 281-298.

STIERLE, Karlheinz. "Identité du discours et transgression lyrique." Poétique 32, 1977, pp. 422-41.

\section{Abstract}

The ways of Saer's writing pursue effects like those the writer identifies in the painting that he preferred, between Van Gogh and Pollock, Estrada and Espino. We conceptualize these ways by means of the figure of a work that seeks to move from the plane to the "impasting", to the "clot", to the pictorialization in relief; and we analyze its relations with Saer's narrative method.

\section{Keywords}

Saer. Glosa. Literature and painting. Spatial form. Argentinian narrative. 